\title{
Family and Lifestyle Factors Mediate the Relationship between Socioeconomic Status and Fat Mass in Children and Adolescents
}

\author{
Isabel Gätjens ${ }^{a} \quad$ Mario Hasler ${ }^{b}$ Romina di Giuseppe ${ }^{c}$ \\ Anja Bosy-Westphal ${ }^{a}$ Sandra Plachta-Danielzik ${ }^{a, c}$ \\ ${ }^{a}$ Human Nutrition, Institute of Human Nutrition and Food Science, Christian-Albrechts \\ University, Kiel, Germany; ${ }^{b}$ Applied Statistic, Agricultural and Food Economics Faculty, \\ Christian-Albrechts University, Kiel, Germany; ${ }^{C}$ Kompetenznetz Darmerkrankungen e.V., Kiel, \\ Germany
}

\section{Keywords}

Mediation analysis $\cdot$ Socioeconomic status $\cdot$ Overweight $\cdot$ Children $\cdot$ Adolescents

\begin{abstract}
Socioeconomic status (SES) is strongly associated with childhood overweight. The underlying mechanism and the role of family and lifestyle factors as potential mediators of this relationship remain, however, unclear. Cross-sectional data of 4,772 girls and boys aged 5-16 years from the Kiel Obesity Prevention Study were considered in mediation analyses. Fat mass (FM) was assessed by bioelectrical impedance analysis and converted into a percent FM SD score (FM\%-SDS). SES was defined by the parental educational level, classified as low, middle, or high. Characteristics of family and lifestyle factors were obtained via validated questionnaires and considered as mediators. In 3 different age groups, the product-of-coefficients method was used to examine age-specific mediator effects on the relationship between SES and FM\%-SDS ( $c$ = total effects) and their ratio to total effects, adjusted for age, sex, puberty, and nationality. The prevalence of overweight was $6.9 \%$. In all age groups, SES was inversely associated with FM\%-SDS as follows: $5-7$ years, $c_{1}=-0.11(95 \% \mathrm{Cl}-0.19$ to -0.03$) ; 9-11$ years, $c_{2}=-0.21$ (95\% $\mathrm{Cl}-0.27$ to -0.14$)$; and $13-16$ years, $c_{3}=-0.23(95 \% \mathrm{Cl}-0.28$ to -0.17$)$. The relationship between SES and FM\%-SDS was fully (5-7 and 9-11 years) and partly (13-16 years) mediated by similar and age-specific mediators, including parental BMI, parental smoking habits, media consumption, physical activity, and shared meals. Overall, these variables resulted in a total mediating effect of $77.8 \%$ (5-7 years), $82.4 \%$ (9-11 years), and 70.6\% (13-16 years). Consistent for both sexes, the relationship between SES and FM\%-SDS was therefore mediated by parental weight status, risk-related behavior within families, and children's and adolescents' lifestyle factors. Strategies for obesity prevention, which are predominantly targeted at socially disadvantaged groups, should therefore address the family environment and lifestyle factors.
\end{abstract}




\section{Introduction}

Socioeconomic status (SES) is known as a major risk factor for childhood obesity [1-3]. The prevalence of overweight and obesity tends to be highest in socioeconomically disadvantaged children and adolescents [4-6]. Parental income and educational level are commonly used as a proxy for SES in children and adolescents, with the latter variable identified as a suitable marker to assess the social status of German children and adolescents and thus to reflect the relationship between SES and overweight in this age range [7]. Results from representative German studies with up to 35,229 children and adolescents aged 3-17 years showed that the highest prevalence of overweight was observed among children and adolescents from families with the lowest level of education and income; boys and girls from low-SES families were about 3 or 4 times as often affected by obesity compared to children and adolescents from high-SES families [3, 8, 9].

The higher risk of overweight in children with a low SES may be explained by a limited budget resulting in access barriers to healthy food or participation in sport clubs $[10,11]$. SES is also known to affect other well-known determinants of childhood overweight like parental weight status and physical inactivity $[12,13]$.

It is therefore hypothesized that family environment and lifestyle factors act as mediators of the association between SES and weight status in children and adolescents. Mediation analysis was used to explore mediatory influences of the family environment (i.e., parental weight status and smoking behavior, shared meals, and dwelling size) and children's and adolescents' lifestyle (i.e., physical activity and media consumption) in the relationship between parental education and fat mass (FM) in 5- to 16-year-old children and adolescents and to examine differences between age groups and sexes.

\section{Materials and Methods}

Cross-sectional data were collected as part of the Kiel Obesity Prevention Study (KOPS), which is an ongoing study started in 1996 in Kiel (Northern Germany) with over 15,000 investigated and partly reinvestigated children and adolescents. The details of the aims, study design, and recruitment procedure are described elsewhere [14, 15].

\section{Study Population}

Participation was voluntary and without any eligibility criteria except the willingness to participate and written informed consent from the parents [14]. Children whose parents had insufficient German language skills were excluded [16]. This study was approved by the local ethical committee of the Medical Faculty of the Christian-Albrechts University (Kiel, Germany; AZ: A 36/95) [14]. Inclusion criteria for the present analyses were a valid residential address in Kiel, complete data of all mediators (selected family and lifestyle factors), available information about FM\% and information on parental school-leaving qualifications. There were no further exclusion criteria.

Due to the specific school grades, the KOPS includes 3 cross-sectional studies in the following 3 age groups: 4,997 first graders (5-7 years old), 4,487 fourth graders (9-11 years old), and 6,263 eighth graders (13-16 years old) [17]. For the present analysis, $69.7 \%(n=$ $10,975)$ were excluded because of incomplete data on FM\% $(n=358)$, mediators $(n=6,340)$, and information on parental school-leaving qualifications $(n=4,277)$. Complete data sets were available for 4,772 children and adolescents ages 5-16-years (2,368 female and 2,404 male participants), stratified as 5- to 7-year-olds (482 boys and 476 girls), 9- to 11-year-olds (709 boys and 762 girls), and 13- to 16-year-olds (1,213 boys and 1,130 girls). Compared with

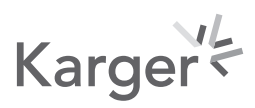


the total study population, the present data set shows a lower prevalence of overweight (6.9\% vs. $9.0 \% ; p<0.05)$, obesity ( $3.2 \%$ vs. $5.6 \% ; p<0.05)$, and a low SES $(16.2 \%$ vs. $23.0 \%$; $p<0.05$ ) in all of the age groups, whereas the percentage with a high SES was higher in the 2 older age groups ( $9-11$ years, $50.3 \%$ vs. $40.8 \%, p<0.05$; $13-16$ years, $59.2 \%$ vs. $42.6 \%$; $p<$ $0.05)$. No other significant differences were observed between the total study population and the subgroup used for the present analyses.

\section{Weight Status and Body Composition}

Measurements of height and weight were conducted by trained observers from the Institute of Human Nutrition and Food Science, Christian-Albrechts University. Body height was determined to the nearest $0.1 \mathrm{~cm}$ using a portable stadiometer (Model 214; Seca GmbH, Hamburg, Germany). Body weight was measured to the nearest $0.1 \mathrm{~kg}$ using a calibrated digital scale (Model 861; Seca GmbH, Hamburg, Germany) with participants wearing light underclothes. BMI (weight $[\mathrm{kg}] /$ height $^{2}[\mathrm{~m}]$ ) was converted into an SD score (BMI-SDS) using German BMI percentiles by Kromeyer-Hauschild et al. [18]. Weight status was classified as: $\leq 10$ th percentile (underweight), $>10$ th but $<90$ th percentile (normal weight), $\geq 90$ th but $<$ 97th percentile (overweight), or $\geq 97$ th percentile (obesity).

Body composition was assessed by bioelectrical impedance analysis (BIA 2000-C; Data Input GmbH, Darmstadt, Germany). Fat-free mass (FFM) was calculated using a populationspecific BIA algorithm derived and cross-validated in the KOPS using the same BIA-devices and air displacement plethysmography as a reference as follows: FFM $(\mathrm{kg})=0.66 \times\left(\right.$ height $^{2}$ $[\mathrm{cm}] /$ resistance $[\Omega])+0.196 \times$ weight $[\mathrm{kg}]+0.157 \times$ reactance $[\Omega]+0.348 \times$ age [years] 12.083 [19]. Percentage body FM (FM\%) was calculated from the difference between body weight and FFM. FM\%-SDS was calculated based on national reference data for German children [20] to adjust for age-dependent changes in FM and it was used as outcome parameter in mediation analyses.

\section{Pubertal Stage}

Pubertal development (female breasts, male genitalia development, and pubic hair growth in both sexes) was self-estimated by adolescents using standardized pictures of Tanner staging on a scale of $2-5$. Up to the age of 9 years, the pubertal stage was assumed to be pre-pubertal (scale 1).

\section{Social Factors}

Social factors of the children and their families were collected using self-reported questionnaires filled in by parents. SES refers to the children's biological or stepparents. SES was defined by the parental education level, based on the highest school-leaving qualification by either the mother or the father. The questionnaire included: "What is your highest schoolleaving qualification?" and "What is the highest school-leaving qualification of your husband/ wife/partner?". Parental education was classified as: (1) low, both parents without or with the lowest school-leaving qualification ( 9 years); (2) middle, at least 1 parent with a middle school-leaving qualification (10 years); or (3) high, at least 1 parent with a high school-leaving qualification (13 years). Single-parent families were classified according the school education of the single parent.

\section{Potential Mediators of the Relationship between SES and FM\%-SDS}

All variables that had been previously found to be associated with childhood overweight in the KOPS [13] were investigated as potential mediators. Information about mediators of family factors were collected using self-reported questionnaires filled in by the parents. Family factors included maternal and paternal BMI (calculated from self-reported height and

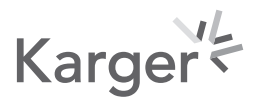


weight), smoking habits of both parents (number of smoked cigarettes per day; the questionnaire included: "Do you smoke?/Does your husband/wife/partner smoke? If yes, how many cigarettes do you/your husband/wife/partner smoke?"), shared meals (number of meals eaten with the whole family per day; the questionnaire included: "How often do you share meals a day with your family?"; response options: $3 / 2 / 1 / 0$ ), and dwelling size (number of residential rooms per number of members living in a household; the questionnaire included: "How many residential rooms do you have (except kitchen and bathroom/WC)? How many adults/children live in this household?"). Information about mediators of lifestyle factors were collected using self-reported questionnaires filled in by parents for children up to the age of 11 years and filled in by adolescents aged 13-16 years. Lifestyle factors included media consumption of the children, combining television viewing and computer playing (h/day; the questionnaire included: "How many hours a day do you watch TV or play computer games?") and physical activity performed in a sports club (h/week; the questionnaire included: "How many hours a week are you doing sports in a sports club?").

\section{Statistical Analysis}

Statistical analyses were performed with IBM ${ }^{\circledR}$ SPSS $^{\circledR}$ Statistics for Windows (version 24.0; Somers, NY, USA) using the PROCESS macro for mediation analysis validated with the statistical software R (version 3.5.1), using the packages lavaan and car. Descriptive statistics of the study population, stratified by age groups, are presented as means \pm SD or numbers (\%). $t$ and $\chi^{2}$ tests were used to determine sex differences. ANOVA followed by Bonferroni post hoc tests and $\chi^{2}$ tests were performed to analyze differences between age groups. $p<$ 0.05 (2-sided) was considered statistically significant. Regression analysis using the residual method was done to adjust dwelling size for the number of members living in a household.

Using the product-of-coefficients method by MacKinnon et al. [21], parallel mediation analyses were performed for each age group to test selected family and lifestyle factors as potential mediators between SES (causal variable) and FM\%-SDS in children and adolescents (outcome). Therefore, the following steps were calculated: (1) total effect of SES on FM\%-SDS measured by the $\beta$-coefficient. A 1-unit increase in SES is associated with a positive or negative increment in FM\%-SDS (path c, c coefficient), (2) associations between SES and all mediators (path a, a coefficient), (3) associations between all mediators and FM\%-SDS adjusted for SES (path $b, b$ coefficient), (4) indirect effects (IE $=a \times b$ ), and (5) the direct effect of SES on FM\%-SDS adjusted for all mediators (path c', c' coefficient). The variance inflation factor was used to assess multicollinearity between significant mediators [22]. To quantify the effect of the mediator on the association between SES and FM\%-SDS, the percentage of the specific indirect effect on the total effect can be calculated as $(a \times b) / c$. To quantify the total mediator effect on the association between SES and FM\%-SDS, the percentage of the total indirect effect on the total effect was calculated. Mediation analyses were tested for full (no direct effect; path c' not significant) and partial mediation (path c' is significant). All mediation analyses were based on simple and multiple linear regression analysis using the bootstrapping technique with 5,000 bootstrap resamples. Age, sex, puberty (tanner stage), and nationality (German vs. non-German) were covariates in all regression models. Significant mediation was established based on $p<0.05$ (2-sided).

\section{Results}

Baseline characteristics of the study population are shown in Table 1. Half of the children were boys. Compared to boys, girls had a higher FM\% (9-11 years: $21.6 \% \pm 7.4 \%$ vs. $19.1 \%$ $\pm 7.2 \%, p<0.001 ; 13-16$ years: $24.7 \% \pm 5.9 \%$ vs. $17.8 \% \pm 6.6 \%, p<0.01)$ and FM $\%$-SDS ( $9-11$

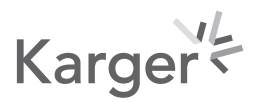


Table 1. Characteristics of the study population stratified by age group

\begin{tabular}{lccc}
\hline Age & $5-7$ years & $9-11$ years & $13-16$ years \\
\hline Subjects, $n$ & 958 & 1,471 & 2,343 \\
Boys, \% & $50.3^{\mathrm{b}}$ & $51.8^{\mathrm{b}, \mathrm{c}}$ & $48.2^{\mathrm{c}}$ \\
Age, years & $6.2 \pm 0.3^{\mathrm{b}}$ & $9.9 \pm 0.5^{\mathrm{c}}$ & $14.5 \pm 0.5^{\mathrm{d}}$ \\
BMI & $15.7 \pm 1.7^{\mathrm{b}}$ & $17.5 \pm 2.6^{\mathrm{c}}$ & $20.4 \pm 2.8^{\mathrm{d}}$ \\
BMI-SDS & $0.04 \pm 0.90^{\mathrm{b}}$ & $0.10 \pm 0.97^{\mathrm{b}}$ & $0.08 \pm 0.89^{\mathrm{b}}$ \\
FM, \% & $21.7 \pm 6.8^{\mathrm{b}}$ & $20.3 \pm 7.4^{\mathrm{b}, \mathrm{c}}$ & $21.4 \pm 7.2^{\mathrm{c}}$ \\
FM\%-SDS & $0.02 \pm 0.97^{\mathrm{b}}$ & $-0.08 \pm 0.90^{\mathrm{c}}$ & $-0.15 \pm 0.90^{\mathrm{d}}$ \\
Weight status & & & \\
$\quad$ Obesity & $31(3.2)^{\mathrm{b}}$ & $50(3.4)^{\mathrm{b}}$ & $69(2.9)^{\mathrm{b}}$ \\
$\quad$ Overweight & $52(5.4)^{\mathrm{b}}$ & $140(9.5)^{\mathrm{c}}$ & $136(5.8)^{\mathrm{b}}$ \\
SES & $192(20.0)^{\mathrm{b}}$ & $261(17.7)^{\mathrm{b}}$ & $252(10.8)^{\mathrm{c}}$ \\
$\quad$ Low & $315(32.9)^{\mathrm{b}}$ & $470(32.0)^{\mathrm{b}}$ & $705(30.1)^{\mathrm{b}}$ \\
$\quad$ Middle & $451(47.1)^{\mathrm{b}}$ & $740(50.3)^{\mathrm{b}}$ & $1,386(59.2)^{\mathrm{c}}$ \\
\hline
\end{tabular}

Values are presented as means \pm SD or numbers (\%) unless otherwise stated. ${ }^{\text {a }}$ According to KromeyerHauschild et al. [18]; significant differences between boys and girls were determined by an unpaired $t$ test; prevalence was compared using a $\chi^{2}$ test; significant differences between age groups were determined by ANOVA followed by a Bonferroni post hoc test. ${ }^{b-d}$ Mean values/percentages not sharing a common superscript letter are significantly different $(p<0.05)$.

Fig. 1. FM\%-SDS (SE) in 958 fiveto seven-year-old children, 1,471 nine- to eleven-year-old children, and 2,343 thirteen- to sixteenyear-old adolescents stratified according to SES and age groups. * Significant differences in FM\%SDS within an age group between low, middle, and high SES (ANOVA; $p<0.05$ ).

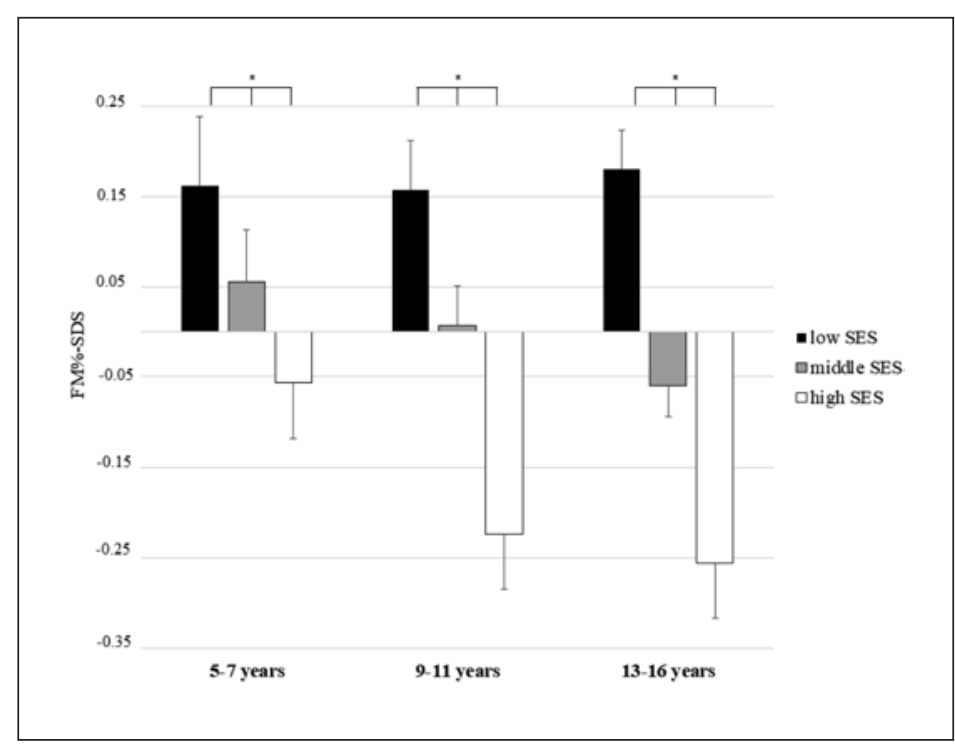

years: $-0.03 \pm 0.95$ vs. $-0.13 \pm 0.93, p<0.05 ; 13-16$ years: $-0.10 \pm 0.88$ vs. $-0.20 \pm 0.92, p<$ 0.001 ), as expected. Children aged 5-7 and 9-11 years were all at the prepubertal stage and most of the 13- to 15-year-old adolescents were at Tanner stages 3 (27.8\%) and 4 (58.1\%). There were no significant differences in the prevalence of obesity in all age groups, whereas the prevalence of overweight was nearly doubled in 9- to 11-year-old boys and girls compared to the other age groups.

Figure 1 shows the mean FM\%-SDS in children and adolescents stratified by age and SES groups. In all 3 age groups, children and adolescents with a low SES had the highest FM\%-SDS, whereas children and adolescents with a high SES showed the lowest FM\%-SDS. SES gradients 


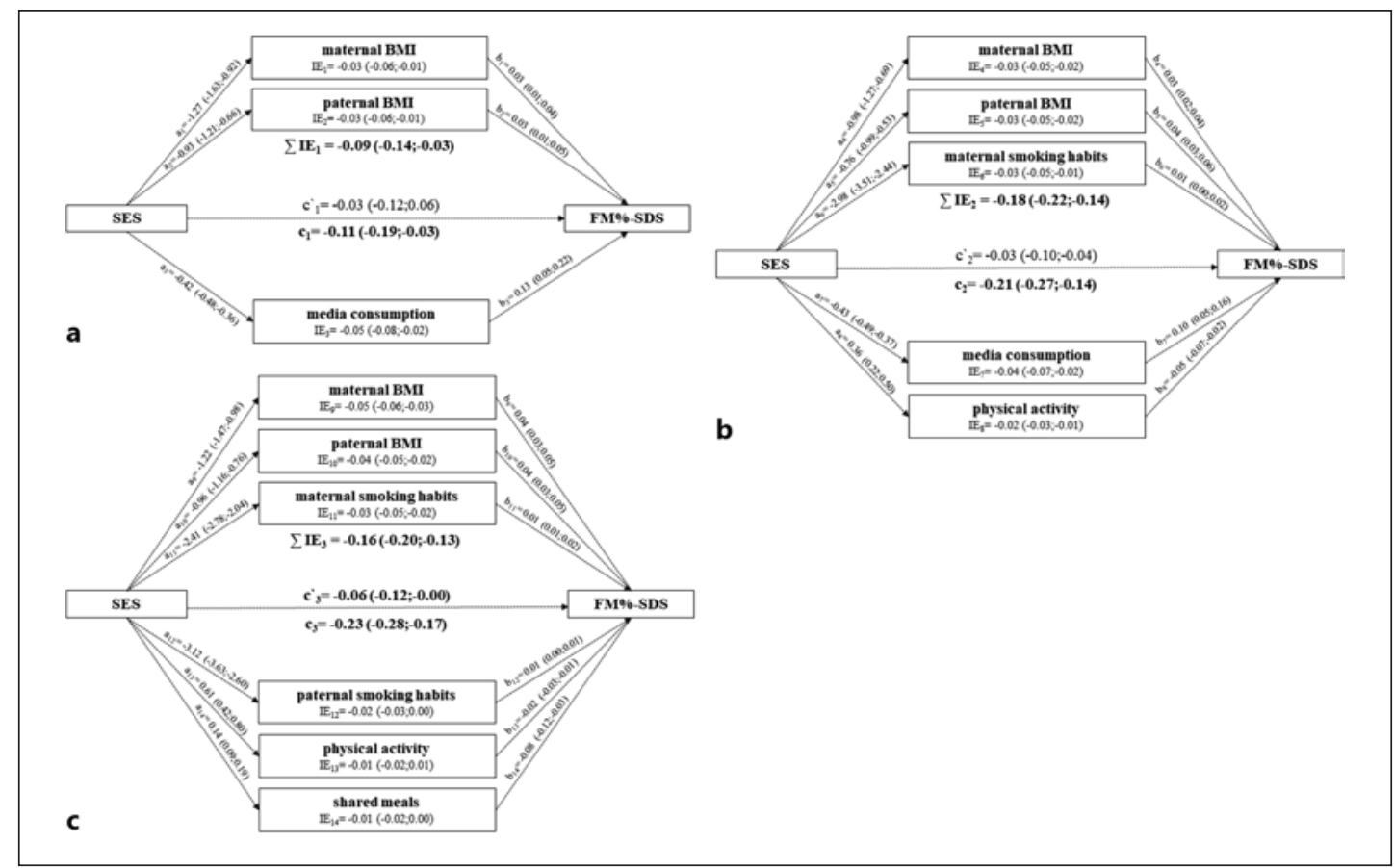

Fig. 2. a Mediation effects of family factors and lifestyle characteristics in 958 five- to seven-year-old children. Covariates: age, sex, and nationality; 95\% CI. b Mediation effects of family factors and lifestyle characteristics in 1,471 nine- to eleven-year-old children. Covariates: age, sex, and nationality; 95\% CI. c Mediation effects of family factors and lifestyle characteristics in 2,343 thirteen- to 16-year-old children. Covariates: age, sex, nationality, and puberty; 95\% CI. IE: indirect effect of SES on FM\%-SDS (IEi = ai × bi); a, path a: effect of SES on the mediator (simple linear regressions); b, path b: effect of the mediator on FM\%-SDS adjusted for SES (multiple linear regressions); path c, total effect of SES on FM\%-SDS (simple linear regressions); path c', direct effect of SES on FM\%-SDS adjusted for all mediators (multiple linear regressions).

increased with age. In low-SES subjects FM\%-SDS were similar between age groups, whereas in middle- and high-SES subjects FM\%-SDS decreased with increasing age groups.

The results of mediation analyses are shown in Figure 2a-c. In each age group, SES had an inverse association with FM\%-SDS. Analyses for effect modification by sex did not show significant differences. Therefore, all subsequent analyses are presented for boys and girls together.

\section{Mediating Effects for 5- to 7-Year-Old Children}

Figure 2a shows the results of the mediation analysis for 5- to 7-year-old children. There was a significant inverse indirect effect on the total effect by maternal and paternal BMI and media consumption. Since the c' coefficient was not significant, the 3 mediators completely mediated the association between SES and FM\%-SDS. The contribution of mediators varied, with the highest effect for media consumption (44.4\%) followed by maternal BMI (33.3\%) and the lowest effect for paternal BMI (22.2\%), resulting in a total mediating effect of $77.8 \%$.

\section{Mediating Effects for 9- to 11-Year-Old Children}

Figure $2 \mathrm{~b}$ shows the results of the mediation analysis for 9- to 11-year-old children. The relationship between SES and FM\%-SDS was mediated by maternal and paternal BMI, maternal smoking habits, physical activity, and media consumption. Since the $c^{\prime}$ coefficient 
Gätjens et al.: Mediation Effects between SES and FM

was not significant, the 5 parameters completely mediated the association between SES and FM\%-SDS. The contribution of mediators varied, with the highest effect for media consumption (23.5\%) followed by maternal BMI, paternal BMI, and maternal smoking habits (all 17.6\%) and the lowest effect for physical activity (5.9\%), resulting in a total mediating effect of $82.4 \%$.

\section{Mediating Effects for 13- to 16-Year-Old Children}

The results of the mediation analysis for 13- to 16-year-old adolescents are shown in Figure 2c. Maternal and paternal BMI and smoking habits, physical activity, and shared meals were significant mediators. Since the c' coefficient remains significant, the 6 parameters partly mediated the association between SES and FM\%-SDS. The contribution of mediators varied, with the highest effect for maternal BMI $(23.5 \%)$ followed by paternal BMI $(17.6 \%)$ and maternal smoking habits $(11.8 \%)$ and the lowest effect for parental smoking habits, shared meals, and physical activity (all 5.9\%), resulting in a total mediating effect of $70.6 \%$.

\section{Discussion/Conclusion}

Mediation analyses revealed that a number of family and lifestyle factors (parental weight status, smoking habits, children's and adolescents' media consumption, physical activity, and shared meals) explain the inverse association of SES with FM\%-SDS. Fully mediating effects were found in younger ages and partly mediating effects were found in 13- to 16-year-old adolescents. Stratifying mediation analyses by age and sex showed small age- but no sexspecific differences in the determinants. Considering all of the mediators together, many variables are consistent with previously detected risk factors of childhood overweight, most notably parental weight status and children's media consumption as a proxy for inactivity [23]. To address the impact of the social gradient, preventive strategies of childhood overweight therefore require the consideration of family and lifestyle factors.

\section{Main Mediators of the Relationship between SES and FM\%-SDS}

Comparing mediation analyses between age groups, the number of mediators increased with age. In 5- to 7-year-old children, the overall mediation effect was explained by the parental weight status and media consumption. However, in 9- to 11-year-old children and 13- to 16-year-old adolescents the inverse relationship between SES and FM\%-SDS was additionally mediated by parental smoking behavior, physical activity, and shared meals as a social factor within the families. Consistent with previous findings, the results of the current analyses show that a low SES is more frequently associated with unhealthy parental behaviors and lifestyle choices in children, which in turn act as determinants of childhood and adolescent obesity. As one of the most important instances of socialization in childhood and adolescence, the family environment conveys basic health-related attitudes and behavior in everyday life $[24,25]$. A possible reason for the age-specific increase in the number of mediators could be the fact that, with increasing age, children may be more strongly influenced by parental health-related behaviors and unhealthy lifestyle choices within the family environment. Additionally, the partly mediating effect in 13- to 16-year-old adolescents might be an indication that other mediators exist that have not been investigated in the present analysis. Factors of the social and built neighborhood environment are potential mediators in this relationship. An association with obesity has been found for numerous built environment characteristics like the lack of green spaces and a higher number of fast food restaurants or social factors like crime, safety, and social capital [26-28]. Two studies that examined mediating influences of eating behaviors including breakfast consumption, sugar-sweetened beverages,

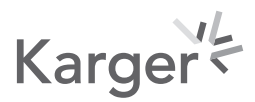


Gätjens et al.: Mediation Effects between SES and FM

and fat intake in 10- to 12-year-old children reported small mediating effects in the relationship between SES and overweight [29,30].

\section{Parental Weight Status}

In all age groups and despite small differences in percentage mediator effects, parental weight status showed the strongest impact on the relationship between SES and FM\%-SDS. Consistent with previous studies, which looked at the separate relationships and not the mediating effects, overweight of the parents was identified as the strongest determinant of overweight in 3- to 16-year-old children and adolescents [13, 31, 32]. The impact of parental weight status on overweight in children is known to be explained by a range of other factors, predominantly a genetic predisposition and parental health-related behaviors including unhealthy food patterns, physical inactivity, and sedentary behaviors [33, 34]. Studies with twins brought up in separate environments have shown that a genetic predisposition to weight gain could account for $60-85 \%$ of the variance in obesity [35]. However, at a given genetic predisposition, the manifestation of obesity depends on environmental and lifestyle factors [36]. Overweight parents were less likely to provide an environment supportive of healthy nutrition and physical activity [34]. In addition, it is known that a low social status is associated with less health knowledge and/or competence about healthy nutrition and physical activity levels, which in turn favors an obesogenic lifestyle of parents and children [37].

\section{Lifestyle Factors}

Age-specific effects are shown for media consumption and physical activity, the importance of which decreases (media consumption) or increases (physical activity) with age. Similar results were also found in a review by Mech et al. [38], where TV viewing mediated the relationship between SES and overweight or obesity in 4- to 9-year-old children [39-42]. Other mediation analyses also revealed that the effect of SES (measured by parental education for the German sample and additionally for parental household income for the US sample) on overweight assessed by BMI percentiles was partly mediated by media exposure [43]. Media consumption explained 35\% of this relationship in 10- to 17-year-old children and adolescents (mean age 12.8 years) and $16 \%$ in the US sample aged $12-16$ years [43]. Another study found no significant mediating effects of media consumption and physical activity on the relationship between SES and overweight defined by waist girth and skinfolds in 11-year-old boys and girls [29]. These discrepant results may be partly due to different measures to define overweight in children and adolescents.

\section{Smoking Habits}

Already in 9- to 11-year-old children the inverse relationship between SES and FM\%-SDS was mediated by maternal smoking behavior, and in 13- to 16-year-old adolescents it was even mediated by smoking behaviors of both parents (Fig. 2b, c). Accordingly, studies that investigated the separate relationships and not mediating effects found positive associations between smoking habits of at least 1 parent and weight status in 4- to 14-year-old children and adolescents [44]. Although there is a lack of studies that can confirm an increasing effect of parental smoking on weight status in children and adolescents with increasing age, other studies, which analyzed the effects of postnatal parental smoking habits in 5- to 16-year-old children and adolescents confirmed a 2.6-fold higher risk of overweight in children of smoking parents compared to children of nonsmokers [13, 31]. In a study with 852 parent-child pairs, a higher prevalence of childhood obesity was shown in children exposed to passive parental smoking compared to children living in smoke-free environments [45]. It can be assumed that the observed mediator effects of maternal and paternal smoking are a proxy for obesogenic

\section{Karger'}


lifestyle factors including physical inactivity, parental overweight, or unhealthy food patterns, which are associated with childhood obesity. Animal experiments, however, suggest biological plausibility for a causal association between maternal smoking in pregnancy and childhood obesity. In rats randomly exposed to nicotine in utero, a higher average weight was reported that might be related to mechanisms like $\beta$-cell apoptosis [46].

\section{Potential Prevention Strategies Derived from Mediator Analyses}

In line with previous studies $[13,31]$, our results confirmed an inverse relationship between SES and overweight in 5- to 16-year-old children and adolescents. Interventions addressing overweight and obesity in children and adolescents differ in their effectiveness across socioeconomic groups [47-49]. Main causes were identified in access barriers to socially disadvantaged groups, resulting in ineffective success of prevention strategies in the lower social classes $[50,51]$. To prevent a further increase in the social gradient in overweight, a deeper understanding of the mechanisms behind the association between SES and FM\%-SDS is required. Our mediation analysis indicates that targeting prevention strategies to socioeconomically disadvantaged children and adolescents, overweight in parents, and risk-related behaviors within families should be considered. Due to the fact that involving parents in preventive measures serves as a barrier and limits the success of family-based interventions in socially disadvantaged groups [47], it could be an important approach to educate elementary or middle school students (the future parents with a low SES) about healthy parenting and a healthy lifestyle. In addition, prevention in children and adolescents should be more focused on alternatives to media consumption in younger age groups and on physical activity in older age groups.

\section{Study Limitations and Strengths}

Cross-sectional data for the present mediation analysis were obtained between 1996 and 2005 and are based on self-reported parental weight, height, and lifestyle factors. Causal effects of the mediating variables on children's and adolescents' weight status can therefore not be deduced from our results. In addition, the present findings may not be generalized to the total population in Germany because, compared to national representative data [52], our study population had a $32 \%$ higher prevalence of a high SES. For the present analysis, we defined SES as parental education without considering other SES indicators (i.e., parental income). Valid information about parental income was difficult to collect from the parents, and therefore the sample size for our present analyses would have been even smaller when including parental income. In addition, previous analyses from our group have shown that parental education is the best marker to characterize the association between SES and overweight in children [53]. Further limitations of this study were the lack of consideration of nutrition-related variables as well as the neighborhood social and built environment as potential mediators of the relationship between SES and overweight. Unfortunately, we could not include data on eating behaviors and neighborhood characteristics (e.g., walkability, traffic density, and crime rate) as potential mediators, because the subgroup with available information on these parameters was too small. Our data enabled us to perform age-specific mediator analyses and thus to determine whether mediators differ in age groups.

In conclusion, the relationship between SES and FM\%-SDS can be fully or partly explained by the mediators parental weight status, risk-related behaviors within families, and lifestyle factors of children and adolescents. The present data provide some evidence for future strategies of health promotion and prevention targeted at families with a low SES, including counselling parents about a healthy lifestyle and educating children and adolescents on alternatives to media consumption in younger age groups and on physical activity in older age groups. Due to the fact that involving parents from a low SES in preventive measures serves

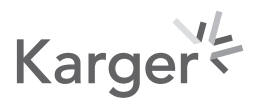


as a barrier in successful intervention, educating elementary or middle school students about healthy parenting and healthy lifestyle could be a better approach to help them lead a healthier lifestyle for their children.

\section{Statement of Ethics}

The parents of the participants have given their written informed consent and this study was approved by the local Ethical Committee of the Medical Faculty of Christian-Albrechts University (AZ: A 36/95).

\section{Conflict of Interest Statement}

The authors have no conflict of interests to declare.

\section{Funding Sources}

The KOPS was supported by the Deutsche Forschungsgemeinschaft (DFG Mü 5.1-5, DFG PL781/2-1), Kompetenznetz Adipositas (Competence Network Obesity) funded by the Federal Ministry of Education and Research (FKZ: 01GI1121A), WCRF, Wirtschaftliche Vereinigung Zucker. We acknowledge financial support from Land Schleswig-Holstein within the funding program Open Access Publikationsfonds. The sponsors of this study had no role in the design, analysis, or writing of this paper. The corresponding author had full access to all the data in this study and has final responsibility for the decision to submit it for publication.

\section{Author Contributions}

S.P.-D. developed the aim of this study. I.G., M.H., and R.G. did the statistical analyses. S.P.-D., I.G., and A.B.-W. interpreted the data. I.G. and S.P.-D. wrote the final draft of this paper. All of the authors discussed the data and approved the final version of this paper. S.P.-D. will act as guarantor for this paper.

\section{References}

1 Langnäse K, Mast M, Müller MJ. Social class differences in overweight of prepubertal children in northwest Germany. Int J Obes Relat Metab Disord. 2002 Apr;26(4):566-72.

2 Lee HJ, Kim SH, Choi SH, Lee JS. The association between socioeconomic status and obesity in Korean children: an analysis of the fifth Korea national health and nutrition examination survey (2010-2012). Pediatr Gastroenterol Hepatol Nutr. 2017 Sep;20(3):186-93.

3 Schienkiewitz A, Brettschneider AK, Damerow S, Schaffrath Rosario A. Übergewicht und Adipositas im Kindesund Jugendalter in Deutschland - Querschnittergebnisse aus KiGGS Welle 2 und Trends. J Heal Monit. 2018; 3(3):60-74.

4 Drenowatz C, Eisenmann JC, Pfeiffer KA, Welk G, Heelan K, Gentile D, et al. Influence of socio-economic status on habitual physical activity and sedentary behavior in 8- to 11-year old children. BMC Public Health. 2010 Apr;10(1):214.

5 Shrewsbury V, Wardle J. Socioeconomic status and adiposity in childhood: a systematic review of crosssectional studies 1990-2005. Obesity (Silver Spring). 2008 Feb;16(2):275-84.

6 Sobal J, Stunkard AJ. Socioeconomic status and obesity: a review of the literature. Psychol Bull. 1989 Mar; 105(2):260-75. 


\begin{tabular}{|c|c|}
\hline Obes Facts 2020;13:596-607 & \\
\hline DOI: 10.1159/000511927 & $\begin{array}{l}\text { (c) } 2020 \text { The Author(s). Published by S. Karger AG, Basel } \\
\text { www.karger.com/ofa }\end{array}$ \\
\hline
\end{tabular}

Gätjens et al.: Mediation Effects between SES and FM

7 Cabrera JC, Karl SR, Rodriguez MC, Chavez C. Investigating socioeconomic status proxies: Is one proxy enough? Pap Present Annu Meet Am Educ Res Assoc. New York; 2018.

8 Müller M, Landsberg B, Kiel S. Interdisziplinäres Konsortium zur Prävention von Adipositas im Kindes-und Jugendalter - PreVENT. Adipositas - Ursachen, Folgeerkrankungen. Ther. 2009 Dec;03(01):39-41.

9 Plachta-Danielzik S, Kehden B, Landsberg B, Schaffrath Rosario A, Kurth BM, Arnold C, et al. Attributable risks for childhood overweight: evidence for limited effectiveness of prevention. Pediatrics. 2012 Oct;130(4):e86571.

10 Drewnowski A. Obesity, diets, and social inequalities. Nutr Rev. 2009 May;67(Suppl 1):S36-9.

11 Gordon-Larsen P, McMurray RG, Popkin BM. Determinants of adolescent physical activity and inactivity patterns. Pediatrics. 2000 Jun;105(6):E83.

12 Langnäse K, Mast M, Danielzik S, Spethmann C, Müller MJ. Socioeconomic gradients in body weight of German children reverse direction between the ages of 2 and 6 years. J Nutr. 2003 Mar;133(3):789-96.

13 Plachta-Danielzik S, Landsberg B, Johannsen M, Lange D, Müller MJ. Determinants of the prevalence and incidence of overweight in children and adolescents. Public Health Nutr. 2010 Nov;13(11):1870-81.

14 Müller MJ, Asbeck I, Mast M, Langnäse K, Grund A. Prevention of obesity-more than an intention. Concept and first results of the Kiel Obesity Prevention Study (KOPS). Int J Obes Relat Metab Disord. 2001 May;25(S1 Suppl 1):S66-74.

15 Plachta-Danielzik S, Landsberg B, Lange D, Langnäse K, Müller MJ. 15 Jahre Kieler Adipositas-Präventionsstudie (KOPS). Ergebnisse sowie deren Einordnung und Bedeutung für die Prävention von Adipositas bei Kindern und Jugendlichen. Bundesgesundheitsblatt Gesundheitsforschung Gesundheitsschutz. 2011 Mar; 54(3):304-12.

16 Plachta-Danielzik S, Landsberg B, Seiberl J, Gehrke MI, Gose M, Kehden B, et al. Längsschnittdaten der Kieler Adipositas-Präventionsstudie (KOPS). Bundesgesundheitsblatt Gesundheitsforschung Gesundheitsschutz. 2012 Jun;55(6-7):885-91.

17 Plachta-Danielzik S, Landsberg B, Lange D, Langnäse K, Müller MJ. 15 Jahre Kieler Adipositas-Präventionsstudie (KOPS). Ergebnisse sowie deren Einordnung und Bedeutung für die Prävention von Adipositas bei Kindern und Jugendlichen. Bundesgesundheitsblatt Gesundheitsforschung Gesundheitsschutz. 2011 Mar; 54(3):304-12.

18 Kromeyer-Hauschild K, Wabitsch M, Kunze D, Geller F, Geiß HC, Hesse V, et al. Percentiles of body mass index in children and adolescents evaluated from different regional German studies. Monatsschr Kinderheilkd. 2001;149(8):807-18.

19 Plachta-Danielzik S, Gehrke MI, Kehden B, Kromeyer-Hauschild K, Grillenberger M, Willhöft C, et al. Body fat percentiles for German children and adolescents. Obes Facts. 2012;5(1):77-90.

20 Kurth BM, Kamtsiuris P, Hölling H, Schlaud M, Dölle R, Ellert U, et al. The challenge of comprehensively mapping children's health in a nation-wide health survey: design of the German KiGGS-Study. BMC Public Health. 2008 Jun;8(1):196.

21 MacKinnon DP, Fairchild AJ, Fritz MS. Mediation analysis. Annu Rev Psychol. 2007;58(1):593-614.

22 Alin A. Multicollinearity. Wiley Interdiscip Rev Comput Stat. 2010 may/Jun ;2(3):370-4.

23 Alghadir AH, Gabr SA, Iqbal ZA. Effects of sitting time associated with media consumption on physical activity patterns and daily energy expenditure of Saudi school students. J Phys Ther Sci. 2015 Sep;27(9):2807-12.

24 Huang H, Wan Mohamed Radzi C, Salarzadeh Jenatabadi H. Wan Mohamed Radzi CWJ bt, Jenatabadi HS. Family environment and childhood obesity: A new framework with structural equation modeling. Int J Environ Res Public Health. 2017;14(2):181.

25 Bauer KW, Neumark-Sztainer D, Fulkerson JA, Hannan PJ, Story M. Familial correlates of adolescent girls' physical activity, television use, dietary intake, weight, and body composition. Int J Behav Nutr Phys Act. 2011 Mar;8(1):25.

26 Suglia SF, Shelton RC, Hsiao A, Wang YC, Rundle A, Link BG. Why the Neighborhood Social Environment Is Critical in Obesity Prevention. J Urban Health. 2016 Feb;93(1):206-12.

27 Lange D, Wahrendorf M, Siegrist J, Plachta-Danielzik S, Landsberg B, Müller MJ. Associations between neighbourhood characteristics, body mass index and health-related behaviours of adolescents in the Kiel Obesity Prevention Study: a multilevel analysis. Eur J Clin Nutr. 2011 Jun;65(6):711-9.

28 Gose M, Plachta-Danielzik S, Willié B, Johannsen M, Landsberg B, Müller MJ. Longitudinal influences of neighbourhood built and social environment on children's weight status. Int J Environ Res Public Health. 2013 Oct; 10(10):5083-96.

29 Dollman J, Ridley K, Magarey A, Martin M, Hemphill E. Dietary intake, physical activity and TV viewing as mediators of the association of socioeconomic status with body composition: a cross-sectional analysis of Australian youth. Int J Obes. 2007 Jan;31(1):45-52.

30 Fernández-Alvira JM, te Velde SJ, De Bourdeaudhuij I, Bere E, Manios Y, Kovacs E, et al. Parental education associations with children's body composition: mediation effects of energy balance-related behaviors within the ENERGY-project. Int J Behav Nutr Phys Act. 2013 Jun;10(1):80.

31 Kleiser C, Schaffrath Rosario A, Mensink GB, Prinz-Langenohl R, Kurth BM. Potential determinants of obesity among children and adolescents in Germany: results from the cross-sectional KiGGS Study. BMC Public Health. 2009 Feb;9(1):46.

32 Reilly JJ, Armstrong J, Emmett P, Ness A, Sherriff A. Early life risk factors for obesity in childhood. BMJ. 2005 Aug;331(7514):454. 
Gätjens et al.: Mediation Effects between SES and FM

33 Danielzik S, Czerwinski-Mast M, Langnäse K, Dilba B, Müller MJ. Parental overweight, socioeconomic status and high birth weight are the major determinants of overweight and obesity in 5-7 y-old children: baseline data of the Kiel Obesity Prevention Study (KOPS). Int J Obes Relat Metab Disord. 2004 Nov;28(11):1494-502.

34 Hendrie GA, Coveney J, Cox DN. Defining the complexity of childhood obesity and related behaviours within the family environment using structural equation modelling. Public Health Nutr. 2012 Jan;15(1):48-57.

35 Allison DB, Matz PE, Pietrobelli A, Zannolli R, Faith MS. Genetic and environmental influences on obesity BT: Primary and secondary preventive nutrition. In: Bendich A, Deckelbaum RJ, editors. Primary and secondary preventive nutrition. Totowa: Humana Press; 2001. p. 147-64.

36 Lobstein T, Baur L, Uauy R; IASO International Obesity TaskForce. Obesity in children and young people: a crisis in public health. Obes Rev. 2004 May;5(1 Suppl 1):4-104.

37 Müller MJ, Danielzik S, Pust S. School- and family-based interventions to prevent overweight in children. Proc Nutr Soc. 2005 May;64(2):249-54.

38 Mech P, Hooley M, Skouteris H, Williams J. Parent-related mechanisms underlying the social gradient of childhood overweight and obesity: a systematic review. Child Care Health Dev. 2016 Sep;42(5):603-24.

39 Beyerlein A, Toschke AM, von Kries R. Risk factors for childhood overweight: shift of the mean body mass index and shift of the upper percentiles: results from a cross-sectional study. Int J Obes. 2010 Apr;34(4): 642-8.

40 Cho YG, Kang JH, Kim KA, Song JH. The relationship between low maternal education level and children's overweight in the Korean society. Obes Res Clin Pract. 2009 Aug;3(3):I-IV.

41 Dubois L, Girard M. Early determinants of overweight at 4.5 years in a population-based longitudinal study. Int J Obes. 2006 Apr;30(4):610-7.

42 Moraeus L, Lissner L, Yngve A, Poortvliet E, Al-Ansari U, Sjöberg A. Multi-level influences on childhood obesity in Sweden: societal factors, parental determinants and child's lifestyle. Int J Obes. 2012 Jul;36(7):969-76.

43 Morgenstern M, Sargent JD, Hanewinkel R. Relation between socioeconomic status and body mass index: evidence of an indirect path via television use. Arch Pediatr Adolesc Med. 2009 Aug;163(8):731-8.

44 Braithwaite I, Stewart AW, Hancox RJ, Beasley R, Murphy R, Mitchell EA; ISAAC Phase Three Study Group. Maternal post-natal tobacco use and current parental tobacco use is associated with higher body mass index in children and adolescents: an international cross-sectional study. BMC Pediatr. 2015 Dec;15(1):220.

45 Schwandt P, Haas GM, Liepold E. Lifestyle and cardiovascular risk factors in 2001 child-parent pairs: the PEP Family Heart Study. Atherosclerosis. 2010 Dec;213(2):642-8.

46 Holloway AC, Lim GE, Petrik JJ, Foster WG, Morrison KM, Gerstein HC. Fetal and neonatal exposure to nicotine in Wistar rats results in increased beta cell apoptosis at birth and postnatal endocrine and metabolic changes associated with type 2 diabetes. Diabetologia. 2005 Dec;48(12):2661-6.

47 Langnäse K, Asbeck I, Mast M, Müller MJ. The influence of socio-economic status on the long-term effect of family-based obesity treatment intervention in prepubertal overweight children. Health Educ. 2004 Dec; 104(6):336-43.

48 Backholer K, Beauchamp A, Ball K, Turrell G, Martin J, Woods J, et al. A framework for evaluating the impact of obesity prevention strategies on socioeconomic inequalities in weight. Am J Public Health. 2014 Oct; 104(10):e43-50.

49 Beauchamp A, Backholer K, Magliano D, Peeters A. The effect of obesity prevention interventions according to socioeconomic position: a systematic review. Obes Rev. 2014 Jul;15(7):541-54.

50 Danielzik S, Müller MJ. Sozioökonomische Einflüsse auf Lebensstil und Gesundheit von Kindern. Dtsch Z Sportmed. 2006;57(9):214-9.

51 Storck C, Dupreé T, Bölcskei PL. Erreicht schulische Gesundheitsförderung Kinder aus sozial benachteiligten Gruppen? Prävent Gesundhförd. 2008;3(2):95-102.

52 Lampert T, Hoebel J, Kuntz B, Finger JD, Lange M, Mauz E, et al. Health inequalities among children and adolescents in Germany . Developments over time and trends from the KiGGS study. J Health Monit. 2019;4(1): $15-37$.

53 Langnäse K, Hesse K, Müller MJ. Einfluß sozialer Faktoren auf die Manifestation und Prävention der Adipositas bei Kindern. Selbstverl. des Inst. für Humanernährung und Lebensmittelkunde der Christian-Albrechts-Univ; 2001. 